\title{
Parents of Children Diagnosed with Autism Spectrum Disorder: What Do They Expect and Experience from Preschools?
}

\author{
Gunilla Westman \\ Andersson (iD) ${ }^{1,2}$ \\ Nanna Gillberg (iD ${ }^{3}$ \\ Carmela Miniscalco iD ${ }^{4}$ \\ 'Department of Education and Special \\ Education, Faculty of Education, \\ University of Gothenburg, Gothenburg, \\ Sweden; ${ }^{2}$ Gillberg Neuropsychiatry \\ Centre, Sahlgrenska Academy, University \\ of Gothenburg, Gothenburg, Sweden; \\ ${ }^{3}$ Department of Business Administration, \\ School of Business, Economics and Law at \\ the University of Gothenburg, \\ Gothenburg, Sweden; ${ }^{4}$ Neuropsychiatric \\ Department and Pediatric Speech and \\ Language Pathology Department, Queen \\ Silvia Children's Hospital \& Gillberg \\ Neuropsychiatry Centre, University of \\ Gothenburg, Gothenburg, Sweden
}

Background: In Sweden, children diagnosed with autism spectrum disorders (ASD) as well as other children in need of special support, according to the law should be provided stimulation and support for their development in their preschools. Parents of children diagnosed with ASD have been shown to struggle to ensure the right to support for their child from society, including in preschool. This study reports parent expectations and experiences when having a child diagnosed with ASD in preschool.

Methods: A questionnaire with 12 open-ended and 9 multiple-choice questions was completed by parents of 26 children ( 3 girls, 23 boys, mean age 4:3 years). The children had been diagnosed with ASD within the last year. The data were analyzed using a qualitative inductive approach with a content analysis of the open-ended questions.

Findings and Conclusions: This study shows that parents expect competence and knowledge about ASD among preschool staff, including the principal. They need continuous dialogue between parents and the preschool staff and expect individualized support for their child. Concerns about their child in preschool frequently occurred.

Keywords: autism spectrum disorder, children, parents, preschool

\section{Introduction}

According to the Swedish Education Act $^{1}$ all children should be provided the stimulation and educational support they need for their learning and general development irrespective of whether they have a diagnosis or not. In addition, the United Nations Convention of the rights of the child became Swedish law in the year of $2020 .^{2}$ There are no national specific education programs directed at children with autism spectrum disorder (ASD) in Sweden but the group is included in the category of children in need of special support. Some of the main goals according to the preschool curriculum can be summarized as that children will be able to:

- "develop their ability to function individually and in a group, handle conflicts and understand rights and obligations, as well as take responsibility for common rules,"

- "develop their ability to listen, reflect and express their own views and try to understand the perspectives of others"

- "develop their use of spoken language, vocabulary and concepts, as well as the ability to play with words, relate something, express their thoughts, put questions, and put forward their arguments and communicate with others". 3 
From the perspective of a child with a diagnosis of ASD, defined as restrictions in social communication, social interaction as well as restricted, repetitive patterns of behavior, interests, or activities, ${ }^{4}$ these goals could be very challenging and, to achieve them, favorable conditions must be provided. Circumstances that need to be considered are group size, clarity regarding routines, instructions etc. Current research has shown that early interventions are important and can improve the areas that are problematic in ASD. It can also affect parental well-being by reducing concerns and stress related to the child's development. ${ }^{5}$ Hence, early identification is important. ${ }^{6,7}$

The problems defined in ASD often lead to major challenges for children in social contexts, such as preschool and school environment. Individualized support in inclusive settings such as preschool has been suggested to be beneficial for children diagnosed with ASD in terms of practicing and generalizing social communication skills. ${ }^{8}$ In Sweden, like in many other countries, Applied Behaviour Analysis (ABA) is a common intensive intervention method in combination with a more eclectic approach provided through the habilitation centers and in collaboration with preschool and the parents. However, due to the heterogeneity in children diagnosed with ASD and in differences in the conditions of different families, the design has been discussed in terms of individualization. ${ }^{9}$ In addition, the collaboration between different actors, such as preschool teachers, principals, habilitation centers, and parents needs to be carefully planned. This is especially important when the main part of the training takes place in the child's preschool where the principal has the ultimate responsibility for the educational work. ${ }^{10}$ Other studies suggest that lower intensity programs in home and preschool are successful. ${ }^{11,12}$

Preschool in Sweden is provided for children from 1-5 years of age and is followed by compulsory school starting at age 6. Statistics from year 2019 shows that $85 \%$ of all Swedish children (1-5 years of age) attended preschool. ${ }^{13}$ The proportion of educated preschool teachers working in preschools at that time was 39.5\%. As for other staff in preschool, 18\% had upper secondary education (Swedish gymnasium) with a particular focus on working with children, and $31 \%$ had other education. On average, each group in Swedish preschools consisted of 15 children.

Preschool teachers have been shown to play a very important role in differentiating children diagnosed with ASD from children without ASD. ${ }^{14}$ This, in turn, indicates that when preschool teachers have adequate knowledge about ASD, children can be identified early in life and gain access to adequate interventions. ${ }^{15}$ In a previous study, parents emphasized the importance of input from preschool in the diagnostic process of the child, and the teachers underscored the importance of being involved. ${ }^{16}$ This hence indicates that collaboration between parents, preschool and other actors is paramount.

Parents of children diagnosed with ASD are often living under elevated levels of stress compared to parents of children with typical development or with non-ASD disabilities. The child's symptoms can have an adverse effect on various areas of everyday family life. Such difficulties can include, for example, raising a child with challenging behavior, economic strain due to parents' need to reduce working hours, or a diminished social and family life. ${ }^{17-20}$ Furthermore, parents often struggle to receive the appropriate support for their child. ${ }^{21,22}$

Research has found that preschool teachers' attitudes toward children diagnosed with ASD correlate with their special education level. ${ }^{23}$ Special Educational Needs Coordinators (SENCOs) play a pivotal role in ensuring school children receive special support, for example supervising the staff working in preschool. A new study found that SENCOs' believe that one of the main reasons why children experience difficulties in preschool is that the preschool does not possess enough knowledge to provide differentiation in the classroom. ${ }^{24}$ Other studies identify that teachers experience significant challenges in meeting children diagnosed with ASD and managing their specific needs, ${ }^{25,26}$ and when teachers experience a lack of knowledge in teaching children diagnosed with ASD, they are also at risk of stress and burnout. ${ }^{27}$ These findings underline the importance of teacher training and continuous work of preparing and creating conditions for meeting all childrens needs at an organizational level.

In Swedish preschools, as well as in preschools in other countries, teachers are working with a diverse range of children with varying individual needs. They are also expected to collaborate with parents in different ways such as sharing daily information, communicating about the child's development and needs etc. ${ }^{3}$ A thematic synthesis about the impact of the family situation undertaken by DePape and Lindsay ${ }^{22}$ demonstrated a variation of parent experiences of the school system. Some parents described negative comments from teachers which they attributed to the teachers' lack of understanding of ASD. Some parents had found themselves educating the teachers when the 
members of staff have not been able to meet the child's special needs, while other parents wanted to be more involved in their child's school situation than granted by the preschool. ${ }^{22}$

Inclusion and participation can be considered as central aspects in relation to social interactions in preschool. These concepts are discussed in a Swedish study, ${ }^{28}$ stating that children can be considered to participate and be included when they attend and are involved in the preschool's everyday activities. What is highlighted is the "experience of" participation, ie the subjective nature of participation is emphasized. In another recent study, ${ }^{29}$ where preschool teachers were asked about their experiences of and reflections on inclusion in preschool the teachers identified the preschool group as the unit for inclusion. Hence the individual perspective was comparatively absent. They also reaffirmed the importance of establishing structures both on an environmental level and overall educational level to create an inclusive preschool for all children, including children in need of special support.

To our knowledge, there are no studies that focus specifically on preschool experiences from the perspective of parents of children diagnosed with ASD within a Swedish context. However, parents, in previous Swedish research, have voiced their concerns about child support in preschool and school as one of many factors leading to stress. ${ }^{21}$ Larcombe et al $^{30}$ studied preparation for transition of preschool children diagnosed with ASD to mainstream schools in Australia from a parent and therapist perspective, and found that social skills and language development were rated as the foremost factor for school readiness. As outlined above, these areas are also deemed as very important objectives in the Swedish preschool curriculum. $^{3}$

The aim of the study was to explore the perceptions of parents, whose children had received an ASD diagnosis within the last year, of the support given in Swedish preschools following a training program offered to teachers. Thus, the study focused on the parents and covered what had been important in terms of their choice of preschool, what they had expected and experienced from preschool regarding educational support for their child, and their communication with the preschool staff.

Research questions:

- What are the parents' expectations from their child's preschool when you have a child diagnosed with diagnosed with ASD?
- What are the parents' experiences of the preschool when you have a child diagnosed with ASD?

\section{Method}

This is a qualitative study, using a questionnaire with open-ended and multiple-choice questions. The openended questions were analyzed to capture parents' expectations and experiences from preschool when having a child diagnosed with ASD. To examine to what extent a specific task was relevant for the group of respondents, the questionnaire's multiple-choice questions were analyzed with descriptive statistics. An overview is presented in Table 1. While a written questionnaire is not comparable to an oral face-to-face interview, where in-depth responses can be elaborated on and followed up with additional questions, ${ }^{31}$ a questionnaire, by contrast can render a higher number of respondents, thereby allowing

Table I Parental Questionnaire (Multiple Choice Questions)

\begin{tabular}{|c|c|}
\hline Question & $\mathbf{N}$ \\
\hline My child is a: & \\
\hline Girl & 3 \\
\hline Boy & 23 \\
\hline $\begin{array}{l}\text { The staff at my child's preschool/ family daycare have } \\
\text { participated in lectures and supervision at the CNC }\end{array}$ & \\
\hline Yes & 23 \\
\hline No & 2 \\
\hline I do not know & 1 \\
\hline The child attends a preschool & 23 \\
\hline The preschool is run by the municipality & 13 \\
\hline The preschool is privately run & 2 \\
\hline The child plans to start preschool & 1 \\
\hline The child plans to start at family daycare & 0 \\
\hline The child attends family daycare & 0 \\
\hline The child stays at home with a parent for the time being & 0 \\
\hline Have your expectations of the preschool been met? & \\
\hline Yes & 16 \\
\hline Partly & 7 \\
\hline No & 3 \\
\hline $\begin{array}{l}\text { Are you worried that your child will not receive } \\
\text { sufficient support in the preschool/family daycare? }\end{array}$ & \\
\hline No & 10 \\
\hline Yes & 8 \\
\hline Yes, on some occasions & 8 \\
\hline
\end{tabular}

(Continued) 
Table I (Continued).

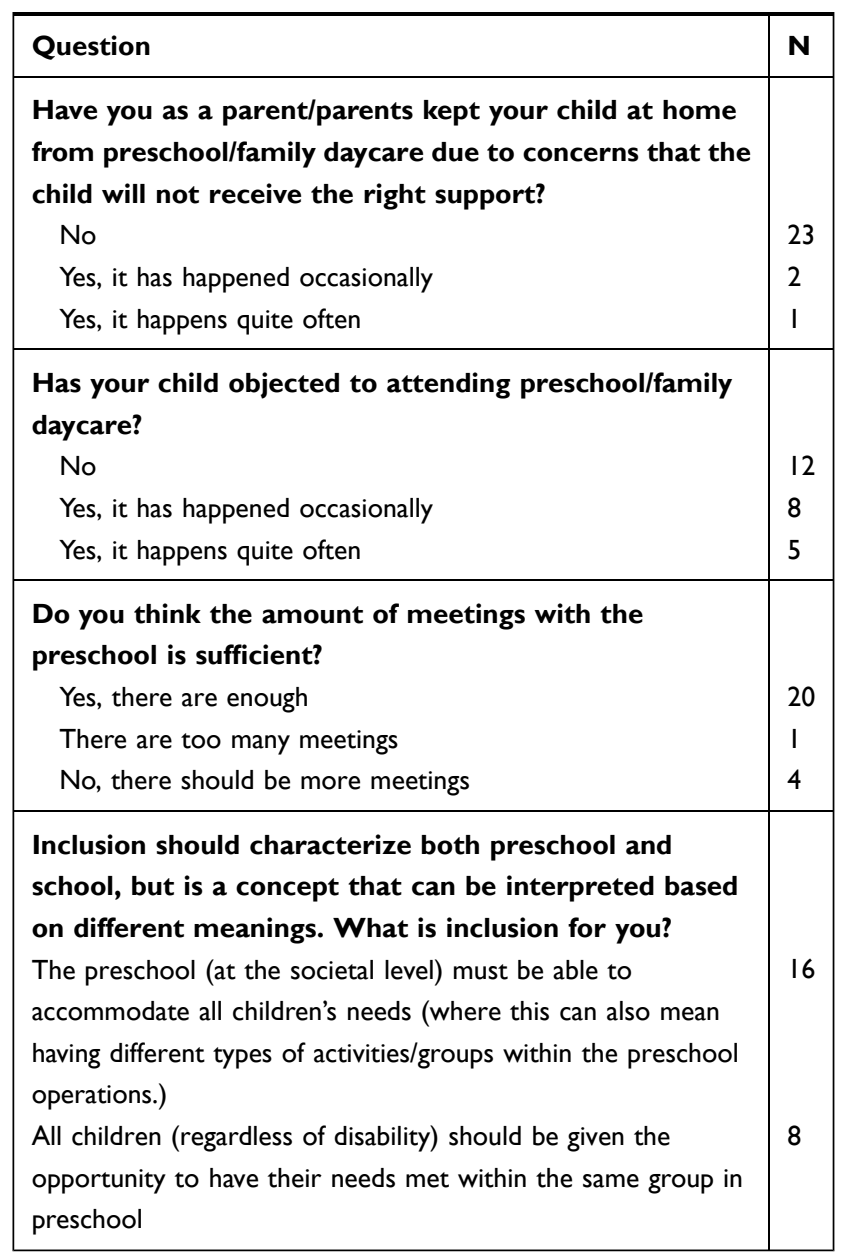

Notes: Not all parents answered all the questions, which explains why the number of respondents differs in some of the questions.

for more points of view and experiences than oral face-toface interviews with fewer respondents.

\section{Participants}

Recruitment was performed through purposive sampling aimed "to select respondents that are most likely to yield appropriate and useful information". ${ }^{32}$ A questionnaire was offered to 71 parents, and parents of 26 children ( 3 girls, 23 boys, mean age 4.3 years) recently diagnosed with ASD at the CNC clinic within the last year answered the questionnaire. In Gothenburg, where the present study was conducted, most preschool children suspected of having ASD or other neurodevelopmental disorders ${ }^{33}$ are diagnosed at the Child Neuropsychiatric Clinic (CNC). The population of the catchment area for the clinic represents a wide range regarding both socioeconomic conditions and cultural background. In this regard, the sample can be expected to represent other parents than those included in the study. After the child has been diagnosed the $\mathrm{CNC}$ offers training programs: one for the parents, and a separate training program for the teachers and other staff working at the specific child's preschool. The parents who were the respondents in the present study, had all participated in this parent group training course within the last year. As this is a qualitative study, it does not claim to represent a population in any statistic sense. It follows from the purpose and research questions as well as the focus on subjective statements, that objectivity in neither attainable nor desirable to strive for.

\section{Questionnaire}

The questionnaire was constructed with open-ended and multiple-choice questions. Nine of the questions were multiple-choice questions (five of these provided opportunity for further comments) and 12 were open-ended questions. The questionnaire was developed using the aim and research questions of the study and were discussed several times and modified by the research group. The aim and research questions, in turn, were based on what was previously known from professional practice in preschools, parents' feedback and evaluations of interventions they had been subject to or taken part in, research, and from other ongoing studies by the present research group. The questionnaires were numbered and pseudonymized before they were sent to the respondents. A written informed consent accompanied the questionnaire, which the respondents signed before sending the form back to the researchers. All respondents signed the consent form.

\section{Analysis}

The study adopted an inductive approach with a content analysis of the written responses to the open-ended questions. ${ }^{34}$ The research questions and the empirical material, which emerged from the questionnaire, constituted the starting point when analyzing the responses, moving forward to identifying different patterns in the collected material. Initially when receiving the empirical material, the responses were written down by the first author in a shared document to provide an overview of the responses. An initial processing of the material was done by adding up the quantitative parts of the questionnaire.

The members of the research group then individually read the empirical material, took notes, categorized the text, and formulated headings. This material formed the basis for discussions within the research group, through 
which themes were identified and agreed upon. A theme here refers to "an abstract entity that brings meaning and identity to a recurrent experience and its variant manifestations". ${ }^{35}$

Defining thematic analysis as an approach aimed "to identify, and interpret, key, but not necessarily all, features of the data, guided by the research questions", Clarke and Braun highlight the active role of the researchers in the theme development processes. ${ }^{36}$ The significance of a theme is primarily determined by the extent to which it manages to capture aspects relevant to the study's research question(s). ${ }^{36}$

In this study, we have aimed to achieve transparency by describing the various steps in our research process. In addition, quotes from the respondents were presented to give readers an opportunity to make their own assessment of the validity of the analysis.

\section{Ethics}

The study was approved by the Swedish Ethical Review Authority (no 2019-01526).

Written informed consent was obtained from at least one of the parents in each case when responding to the questionnaire. The obtained parental informed consent included publication of anonymized responses.

\section{Findings}

\section{Findings from Multiple-Choice Questions}

Findings obtained from the multiple-choice questions are presented in Table 1. The majority of the children attended a public preschool $(\mathrm{n}=13)$ and two children attended a private preschool. One child was waiting to start preschool. Most of the respondents found their expectations of the preschool met $(n=16)$, seven parents were partly satisfied, while three respondents answered that the preschool did not meet their expectations at all. The majority of the parents were often or sometimes worried that their child did not receive the support that was needed in preschool $(\mathrm{n}=16)$, and ten parents stated they were not worried. Three parents had kept their child at home out of concern for the child's overall situation in preschool, but the majority ( $\mathrm{n}=23$ ) had not. Circa half of the respondents answered that their child had objected to entering preschool, five of which parents said it happened quite often. The majority said that they were satisfied with the amount of meetings offered by the preschool $(n=20)$. Several respondents said they had scheduled meetings with the staff twice every half-year, and some said they had meetings every week. Furthermore, many parents highlighted the importance of meeting daily for spontaneous chats when leaving or picking up the child.

\section{Findings from Open Ended-Questions}

\section{Expectations of Preschool Having the Preschool Nearby the Home as Well as Your Own Impression of the Specific Preschool is Important When Choosing a Preschool}

The choice of preschool, was for most of the respondents, based on the fact that the preschool was located nearby the home, as well as what was primarily offered by the municipality. The reason could also be that they had siblings who attended the same preschool and thus this choice was deemed the most practical for the family.

The older sibling attends that preschool. (13)

The reason is that it is a good preschool and it is also located close to where we live. (1)

Even though the preschool was the one closest to home, several parents had also researched how the preschool worked with children in need of special support, and what experience the teachers had in working with children diagnosed with ASD. This had been done by collecting information from eg neighbors who had children in this current preschool, but additionally by the parents themselves visiting the preschool to form their own opinion. Education and experience of children diagnosed with ASD among the staff was considered as very important by the parents.

The preschool is right by our home. Before choosing this preschool we talked to the preschool manager. We wanted to know if they had had children with autism at the preschool and whether they had any formal training. When we received satisfactory answers, we chose that preschool. (20)

We visited several preschools and this was the place that made the best impression through small children groups and engaged staff. (14)

Close to home as well as good reviews of the preschool from neighbors etc. (9) 


\section{Commitment, Competence, and Attitude Among Staff}

Most of the responding parents expected their children to be well received by the staff, to be offered support in various activities, but above all be given the conditions for a positive development and feel safe and secure during their time in preschool. For the respondents, it was important to find a genuine engagement among the staff and a willingness to meet the need of all children, even those with more specific needs, eg when having ASD.

We expect more support and understanding for our son's difficulties, challenges, and possibilities. For example that he shall have the same right to development of his ability as children with "normal" skills have to reach their level. That's how the Education Act is written ... (13)

Engagement and willingness to adapt and learn more about autism and my child. (3)

High expectations of the staff's competence emerged, both principal as the leader of the preschool's local organization, and the preschool teachers and other staff working directly with the child. Several respondents underlined the importance of not only being well informed about ASD, but also having strategies for sustained collaboration, internally, as well as with other actors, as a prerequisite for a child's positive development.

We expect the preschool to understand and know how to handle a child who has autism or another disability. For us, it is really important that the child receives appropriate support. (1)

For the staff to educate themselves if needed as well as continuously working on promoting his interaction, communication, confidence, and development. Collaborating with habilitation services. (19)

\section{Dialogue Between Staff and Parents}

Several parents wanted a continuous follow-up of the pedagogical work regarding their child and a regular dialogue with the staff. They called for time to be able to talk to the staff about the child in the daily chats when leaving or picking up the child in preschool.

... continuous follow-up and evaluation. ... Daily dialogue ... (14)

... more patience and flexibility from the staff ... Room for communication (between staff and parents). (5)
Parents became concerned when feedback and follow-up on interventions and strategies had not reached them. In this context one of the respondents expressed the following:

He needs more support with the language. Cannot really tell what he has received and learnt and also don't meet the special education teacher on site that often. Don't get any feedback from the preschool. (18)

Some of the respondents had the impression that the principal did not have sufficient knowledge. They felt that it was the parents' own responsibility to contact the principal and point out that their child needed extra and adapted support. This became an extra concern and additional task for the parents, which they considered should have been the principal's responsibility.

Have talked to the manager but doesn't seem to have that much knowledge, or she would have asked for extra help for our child. We had to call and talk about the need for extra support. (18)

\section{Positive Experiences}

\section{The Role of the Preschool Staff}

The staff's individual roles and relationship to the child were of great importance for many of the respondents. Respondents valued the fact that the staff turnover was low. Furthermore, the respondents underlined the importance of a good and stable relationship between the child and all the members of staff, as well as between the staff and the parents. In addition, the support they experienced from a committed principal who demonstrated knowledge about children in need of special support was an important positive factor.

We have experienced the preschool in a very positive way in their treatment and willingness to help the child thrive. Great understanding. Also want to point out that it has been/is a safe, stable group of staff who also to a large extent has contributed to the positive experience. (5)

We feel that the preschool manager is very engaged, wants the best for the child and also knows of children with impairments. We experience that the preschool manager is doing her best for the child. (1)

Education and knowledge among the staff were important in relation to trust in preschool and the pedagogical work in relation to the child. This was both about the staff having a basic formal education about children's 
development and needs, and specific knowledge about children diagnosed with ASD.

Trained staff with experience handling different children with different needs. Create groups, activities based on the children's strengths and weaknesses. Have also been able to support us parents. (2)

We think it's a good choice since the preschool teachers are trained in development and follow the structure of pedagogy at a young age. Can give $\mathrm{X}$ support to the extent that they are able. (10)

Great experience. The three regular teachers have worked with children with similar difficulties for many years. Do not experience that knowledge is lacking. Perhaps a bit poor understanding sometimes of reactions coming out at home (sometimes). (7)

When the staff have shown their own initiatives by educating themselves in ASD and indicated a personal responsibility, this has instilled additional trust in the responding parents concerning the preschool. This could have meant that they had participated in the training offered at the $\mathrm{CNC}$ in connection with the child's diagnostic assessment, or they sought knowledge in other ways to be able to implement appropriate pedagogical strategies in the preschool's activities.

The staff has taken initiative to obtain knowledge about autism as well as taken measures such as visual support and manual signs, kept a dialogue with us, adjusted situations to his special needs and come up with suggestions regarding food etc. (19)

The teachers show great interest in learning to meet $\mathrm{X}$ and attend training through habilitation services and take part of guidance offered by CNC. (10)

They are competent and flexible. What they didn't know before they made sure to learn and implement. (23)

We are very grateful for the fantastic teachers and preschool that we have. That they have attended IBT training and are so engaged and eager to see all children's unique abilities. They bring out our son's strengths in the group in an amazing way. (12)

After the staff had participated in the training at $\mathrm{CNC}$, several respondents experienced their child's welfare and development in preschool improve. Despite the fact that not all conditions allow the staff to implement their knowledge were in place, the mere fact that the staff endeavored to learn about the child's disability created a sense of trust in the preschool on the part of the parents.

We believe that the members of staff at the preschool know how to handle a child with autism and similar impairments all thanks to the training they have received at CNC. (1)

They have had several children with autism and all of the staff has had training at CNC. (20)

They have no previous experience but have been very forthcoming and seen the training as an asset. They wish that they could help him more, but the time is not there, but the will is definitely there. (16)

The teachers have greater understanding, and we see how they struggle more with him than with other children. (21)

\section{Adjustments in Preschool}

Some respondents described that almost immediately after the child's diagnosis or staff received training, they noticed a change regarding the general strategies in preschool. When the parents had been involved in the planning and evaluation of interventions, positive communication between parents and preschool staff ensued. Important parts of daily routines had changed in preschool and even though the whole group of children benefited, it is perceived to have been primarily based on the child with autism and his/her needs.

The preschool has developed a plan for X. They have also acquired an additional resource for $\mathrm{X}$ part-time. The communication with the preschool is good. Ongoing follow-up of X's development. (17)

Very positively. Everyone understands what I want my son to get help with. Everyone has been involved and shown great interest and knowledge about autism. (23)

They often have him in a small group of around 5 people. -" Action plan" exists, however it's a bit "fluffy". - The teachers have come to the habilitation centre twice. (13)

More than one example of pedagogical adaptations and strategies that were perceived as positive were described by several respondents. One example given was that smaller groups were created which simplified life for the child both in terms of interaction, communication, and participation in various activities. Further examples included communication support in the form of visual support, sign support and other language training, adapted games and play situations, etc. 
Yes they are using signs, made smaller groups of children. If the child is worried, he gets to walk away and be left alone by the other children. (15)

Smaller play groups with teachers participating in the play - Visual support - Extended preparations prior to changes - Well-thought-out groups for outdoor play Reflection when something has gone wrong, active learning pertaining to him as a person and his strengths and weaknesses. (2)

Some parents reported that they noticed results regarding social training, where the child had made friends as a result of the pedagogical work, and where the child now played a natural part in the group with other children.

... training of social interaction individually and in groups (23)

Now the teachers are so wonderful, and our son is developing and has friends. He has been placed in a social context that we don't want to change. (12)

\section{Negative Experiences}

\section{Lack of Knowledge About the Child's Needs Among the Staff}

Although many positive factors were highlighted by respondents, there were also several examples of the opposite. Some parents felt that the staff's knowledge regarding children diagnosed with ASD and especially about their specific child's needs was lacking, or that the staff's knowledge about the child's needs would not be visible in the concrete activities. Staff changes, temporary substitutes etc are highlighted as risk factors for the child's needs not being met to the desired extent.

... have difficulty assessing their knowledge. Feels like they are treating our boy like everyone else. Only one preschool teacher has attended training at CNC. Also, most of the time there are temps there. (18)

They have limited knowledge. It could be a lot better. (7)

There are no sufficient interventions that we are pleased with or can tell you about besides him getting visual support. (18)

As the staff, including the principal, did not clarify what support could be offered, or the support did not become visible in the preschool routines, some of the respondents described how they as parents took on the role of training the staff and being responsible for transferring the knowledge they had received following the parent training at CNC.
As a parent I have to teach them things I have learnt during the training course. (21)

Some of the responding parents also described that the preschool staff had a different opinion of the child than what emerged both from the parents' description of the child and from the result from the diagnostic assessment. In these cases, the staff had not agreed that the child had ASD and thus, according to the parents, they had not used the recommended pedagogical strategies. This in turn has given rise to concern among parents.

From an external point of view the preschool has adopted the information but consistently refused to use it in practice, saying that "there is nothing wrong with the child" etc. (3)

... have received quite poor understanding from the manager. (7)

\section{Parents' Concerns About the Child in Preschool}

Several parents expressed concern about the child's wellbeing in preschool. Many responses described the child to teacher ratio as being too high. Some of the parents were worried that the preschool could not guarantee the child's safety due to the staffs' workload, and that their child could then get into problematic situations because the child could not communicate their needs.

I am concerned that there are too few teachers and too many children and that this can make it difficult to spot if something happens. (22)

My children cannot talk, so they cannot explain what has happened. I am worried! (8)

Concerns about the child's development also emerged among the parents' responses. This was considered as a consequence of the child not receiving sufficient stimulation and support in preschool, where the lack of time and resources was stated as one of the reasons. As the parents in many cases need to work full time to make the family's finances work, the child also spends the corresponding amount of time in preschool. Thus, it is the preschool that provides the extra support for the child during the weekdays and not the family home.

The development is slow. He spends more of his waking time at preschool than he does at home (like most children since we both work $100 \%$ ). We sometimes find him a bit "lost" in the preschool playground since he needs an adult who "includes" him and sometimes helps him to change 
activity. The preschool manager says that she cannot guarantee $50 \%$ additional teacher resource in the future etc etc. A lot of worry all the time. (13)

The child started making signs but that has now ceased. $\mathrm{He}$ is content at preschool but it doesn't feel like he gets any input for development. (15)

One of the respondents said that their child reacted extremely strongly when going to preschool and felt very bad, as what the parents described as a result of the lack of support in the preschool, and further resulted in the parents being forced to keep the child at home.

He cries and screams and panics ... Our child has been assessed by doctors to have hit a wall from the lack of support and is therefore at home. (3)

In addition, there were more examples of children not wanting to go to preschool and several parents described that the transition of going from home to preschool was challenging. For some children this had ameliorated with time and the child had felt safer at preschool.

Much more seldom now. A couple of years ago it was every day. (5)

\section{Parents' Definitions of Inclusion in Preschool}

The parents' answers to the question of what inclusion meant from their perspective are reported in Table 1 and were dominated by the alternative:

The preschool (at the societal level) must be able to accommodate all children's needs. (where this can also mean having different types of activities/groups within the preschool operations)

Some further comments also emerged, underlining the variation of needs based on individual conditions.

That all children shall have the right to having their needs met and tailored based on what works best for the child. Where there is an overview and all teachers learn the child equally and where you introduce and explain to the children about differences. (10)

Very important to keep an extra close watch since children with autism to a varying degree are different and consequently run the risk of being exposed (be bullied). Important that the environment isn't too chaotic/loud as that is often bothersome. Important to not talk over the heads of the children. (22)
Are very grateful that our son attends a preschool that is adapted to children with communication difficulties. Do not think he would have developed the way he has without that help. Would have liked to see more of that within preschools and schools. (11)

These quotes, and the variation of the responses of the alternatives given in the questionnaire and presented in Table 1, indicate that many respondents believe that a variety of solutions are needed within the preschool organization due to the variety of children's needs. Not least for children diagnosed with ASD.

\section{Discussion}

According to the Education Act $^{1}$ and the preschool curriculum $^{3}$ all 1-5-year-old children should have access to preschool in Sweden. In addition, the preschool has an obligation to meet the needs of all children for a positive development. This study aimed to evaluate parents' expectations and experiences of preschool when having a child diagnosed with ASD. As previous research has underlined the importance of early interventions, ${ }^{5}$ and given that the majority of Swedish children from 1-5 years of age attend preschool, the educational role in preschool becomes central for the child's development and learning. ${ }^{13}$ Parents of children diagnosed with ASD often experience stress in their daily life. ${ }^{17-20}$ Thus it is important that the preschool situation is positive, both in terms of the child's well-being and learning, and for the parents' ability to juggle everyday demands.

In terms of expectations of preschool, the respondents in this study valued the preschool being located near their home. The quality of the preschool in general was valued by both the parents themselves and through information from other parents. Previous studies suggest that parents often find themselves accountable for ensuring that their child is receiving the right and sufficient support, ${ }^{21,22}$ which is in line with the present study's results.

Being able to choose the preschool that an older sibling was attending (or had been attending) was rated highly for practical reasons, as parents were able to drop off and pick up their children at just one preschool. One can also speculate that it is also based on the fact that trust has already been established in relation to the staff, which also has been suggested as important for a positive collaboration between parents and staff. ${ }^{22}$ In the present study, several parents expressed expectations of a regular and positive dialogue with the preschool. When the expectations were not met, it raised concerns about the child's 
situation in preschool. Although the respondents stated their basic expectations on preschool had been met, there were important parts that were still perceived as problematic which are further discussed below.

The parents expected both teachers and the preschool principal to be equipped with the necessary skills to be able to meet the child's needs. Current Swedish research ${ }^{24}$ has however demonstrated that, according to SENCOs (supervising in preschool), preschool employees do not have sufficient knowledge to accommodate to children's diverse needs. In relation to this research, the current study identifies a gap between parents' expectations on preschools and the preschool situation that they are presented with. This result underlines the importance of investing in further education for teachers and other staff in preschool, both in teacher education but also as continuous and regular training. In order to meet children's needs, key actors must keep abreast of societal changes, new knowledge, and changing preschool conditions. This also came to light in the study by Andersson et $\mathrm{al}^{21}$ which was conducted in the same research area as the present study, and where several parents experienced a lack of sufficient knowledge about ASD among various key actors in society, which raised concerns that the child would not receive the right support.

The experiences of a good relationship between parents and preschool staff was highly valued. Most of the respondents were satisfied with the amount of meetings the preschool arranged and considered the daily meetings when leaving and picking up the child very important. Several respondents pointed out that a stable staff group, with a low staff turnover, contributed strongly to positive relationships. This included relationship between the parents and the staff as well as between the child and the staff. Various factors could of course contribute to many staff changes taking place at preschool, but one could speculate on some possible reasons. One reason could be a lack of educated staff, where staff without training are working in preschool for a short period of time before moving on to other work or starting their education. According to the Swedish National Agency for Education, ${ }^{13} 31 \%$ of the staff in Swedish preschools in 2019 did not have adequate training for working with children. Another possible reason could be that the educated staff's workload becomes too considerable, which in turn results in a desire to change workplace. Lack of knowledge among teachers, for example knowledge of ASD, often leads to a low self-efficacy, which inevitably becomes a risk factor for stress and burnout. ${ }^{27}$ Consequently, the lack of competence could be linked to an increased staff turnover affecting children, parents, and actors working within the organization. This further strengthens the argument of investing in education, both for the staff working close to the children, and for the principal and other leaders at an organization level. ${ }^{23-25}$

Both positive and negative experiences recounted by the respondents could be linked to the competence of staff and principals. Meeting a principal who demonstrates understanding and commitment inspires confidence. The commitment, however, also has to be visible in the daily practice of the preschool. The organization as a whole affects how the activities themselves can be carried out. The important role of the principal in this respect is also highlighted in previous research. ${ }^{10}$ If there is a lack of competence, the organization has to provide opportunity for further training. In several studies the significance of education has been underlined. ${ }^{23-26}$ The respondents in the present study describes that even when there is a perceived lack of competence among staff, a certain level of trust can still be achieved if the parents experience an ambition on the part of staff to obtain more knowledge. When the staff agreed to participate in the training offered by the $\mathrm{CNC}$, the parents saw an engagement leading to a greater trust in the staff. Several examples appear in our findings where respondents are highlighting this trust in engaged staff, even if the school has not been fully able to accommodate all the adjustments required.

Early interventions have been shown to be pivotal for a positive development in children diagnosed with ASD. ${ }^{5}$ With this in mind, it is also important that preschool settings are adjusted accordingly, as well as have pedagogical strategies in place. There was a variation in the respondents experiences regarding adjustments, but when appropriate adjustments were made soon after diagnosis, it was highly valued by parents and gave them trust in the preschool staff. The mentioned positive adjustments were eg improved communication and the arrangement of smaller groups making it easier for the child to play and interact with other children. Some parents also could see results of the strategies related to social interaction where they said that the child had made friends. In contrast, when the parents experienced a lack of knowledge and engagement among the staff, they worried about the child in different ways. When the staff or the principal was unclear about what kind of support the child was receiving in preschool, it affected the parents, causing worry and stress. In other words, lack of transparency in itself could lead to stress and lack of trust among parents. This is also in line with previous research 
where parents have articulated a wish to be more closely involved in the school situation. ${ }^{22}$ The majority of the respondents in the present study said that they worried about the support their child received in preschool, even if the extent of concerns varied.

The high child to teacher ratio was a concern for many parents. They were not only concerned with the safety of the child but also that the child was marginalized, and that the child's specific needs were not noted in preschool. One parent said they had to keep the child at home as the child was reacting very negatively regarding preschool. As previously mentioned, parents of children diagnosed with ASD often have difficulty juggling the requirements of everyday life having a stressful life situation. ${ }^{17,19,20}$ If the child must be taken out of preschool and alternative arrangements have to be made, it leads to additional challenges for the parents in their everyday life, not least when their economic situation becomes affected.

The meaning of inclusion and what the term really means in practice has been frequently discussed. ${ }^{28}$ The majority of the respondents underlined the importance of meeting all children's individual needs. Most of the respondents agreed with the alternative in Table 1, that the preschool on an overall level should meet all children's individual needs, which in practice could imply the requirement of a variation of groups within the preschool organization. Children diagnosed with ASD and other ESSENCE problems constitute a very heterogeneous group ${ }^{6,8}$ which creates a need for individualization of support. To be able to achieve this, knowledge about ASD and other developmental problems in young children is crucial. Thus, it again becomes important to note the importance of educating staff, not to mention leaders of the organization, to enable the right prerequisites for a successful pedagogical environment for children diagnosed with ASD and other children in need of special support.

\section{Limitations}

Although this study increases our understanding of parents' expectations and experiences from preschool when having a child diagnosed with ASD, there are some limitations that need to be acknowledged. Since the participants are all from the same region and diagnosed at the same clinic, their experiences might not be representative of Sweden as a whole. The parents had participated in the same parent training and the staff had all been offered the same training from the clinic. This could be seen as a limitation in terms of transferability. However, the preschool in Sweden has a common curriculum and is covered by the Swedish Education Act. ${ }^{1}$ Data were collected through questionnaires with multiple-choice and open-ended question, which could be a limitation in terms of amount of information. No additional data of country of birth, language spoken at home or socioeconomic status were collected in the questionnaire. This may also limit the transferability of our findings. However, the chosen method yielded information from a larger group of parents than, under the given time constraints, would have been possible with face-to-face interviews.

\section{Conclusions}

This study shows that parents of children diagnosed with ASD expect staff and principals in preschools to have competence and knowledge of ASD. They also request regular communication with the staff regarding the child's general situation in preschool, but also about interventions and support and how these strategies are beneficial to their child or not. Parents also expect individualized support for their child and that the preschool organization accommodates different solutions for individual needs. The majority of the parents in this study stated that their basic expectations had been met but concerns of their child in preschool frequently occurred. In addition, a deep understanding of parental expectations may direct clinicians to implement targeted and personalized intervention on the single child, increasing the overall family well-being.

\section{Acknowledgments}

The authors thank all the parents who participated in this study and kindly shared their experiences.

\section{Funding}

This study was supported by grant from the AnnMari and Per Ahlqvist foundation.

\section{Disclosure}

The authors declared that they have no conflict of interests. This study was conducted in accordance with the Declaration of Helsinki.

\section{References}

1. SFS (2010:800). Skollag (Education Act), 2010: 800. (Swedish). Available from: https://www.riksdagen.se/sv/dokument-lagar/doku ment/svensk-forfattningssamling/skollag-2010800_sfs-2010-800. Accessed September 10, 2021.

2. SFS (2018:1197). United Nations Convention of the rights of the child. 2018: 1197. (Swedish). Available from: https://www.riksda gen.se/sv/dokument-lagar/dokument/svensk-forfattningssamling /lag-20181197-om-forenta-nationernas-konvention_sfs-2018-1197. Accessed September 10, 2021. 
3. Skolverket. Curriculum for preschool: Lpfö 18. Stockholm: Skolverket; 2018. Available from: https://www.skolverket.se/publika tionsserier/styrdokument/2019/curriculum-for-The-preschool-lpfo -18. Accessed September 10, 2021.

4. American Psychiatric Association. Diagnostic and Statistical Manual of Mental Disorders (DSM-5). American Psychiatric Pub; 2013.

5. Zwaigenbaum L, Bauman M, Choueiri R, et al. Early identification and interventions for Autism spectrum disorder: executive summary. Pediatrics. 2015;136(Supplement):S1-S9.

6. Gillberg C. The ESSENCE in child psychiatry: early symptomatic syndromes eliciting neurodevelopmental clinical examinations. Res Dev Disabil. 2010;31(6):1543-1551.

7. Tsang L, How CH, Yeleswarapu SP, Wong CM. Autism spectrum disorder: early identification and management in primary care. Singapore Med J. 2019;60(7):324-328.

8. Barton E, Lawrence E, Deurloo K. Individualizing interventions for young children with autism in preschool. J Autism Dev Disord. 2012;42(6):1205-1217.

9. Roane H, Fisher W, Carr J. Applied behavior analysis as treatment for Autism spectrum disorder. J Pediatr. 2016;175:27-32.

10. Olsson I, Roll-Pettersson L. A didactic perspective on negotiations and collaborations between different actors within the Swedish support system: children with Autism spectrum disorders included in community-based preschool settings. Nordic J Stud Educ Policy. 2020;6(1):58-68. doi:10.1080/20020317.2020.1711561

11. D'Elia L, Valeri G, Sonnino F, Fontana I, Mammone A, Vicari S. A longitudinal study of the TEACCH program in different settings: the potential benefits of low intensity intervention in preschool children with Autism spectrum disorder. J Autism Dev Disord. 2014;44(3):615-626.

12. Fernell E, Westerlund J, Höglund Carlsson L, et al. Early intervention in 208 Swedish preschoolers with autism spectrum disorder. A prospective naturalistic study. Res Dev Disabil. 2011;32(6):2092-2101.

13. Skolverket. Beskrivande statistik (Swedish); 2020. Available from: https://siris.skolverket.se/siris/sitevision_doc.getFile?p_id=549823. Accessed September 10, 2021.

14. Jobs EN, Bölte S, Falck-Ytter T. Spotting signs of autism in 3-yearolds: comparing information from parents and preschool staff. J Autism Dev Disord. 2019;49(3):1232-1241.

15. Vakil S, Welton E, O’Connor B, Kline LS. Inclusion means everyone! The role of the early childhood educator when including young children with autism in the classroom. Early Childhood Educ J. 2009;36(4):321.

16. Andersson GW, Miniscalco C, Gillberg C. Preschoolers assessed for autism: parent and teacher experiences of the diagnostic process. Res Dev Disabil. 2014;35(12):3392-3402.

17. Estes A, Olson E, Sullivan K, et al. Parenting-related stress and psychological distress in mothers of toddlers with Autism spectrum disorders. Brain Dev. 2013;35(2):133-138.

18. Hartley SL, DaWalt LS, Schultz HM. Daily couple experiences and parent affect in families of children with versus without autism. J Autism Dev Disord. 2017;47(6):1645-1658.

19. Hayes SA, Watson SL. The impact of parenting stress: a meta-analysis of studies comparing the experience of parenting stress in parents of children with and without Autism spectrum disorder. J Autism Dev Disord. 2013;43:629-642.
20. Karst JS, Van Hecke AV. Parent and family impact of Autism spectrum disorders: a review and proposed model for intervention evaluation. Clin Child Fam Psychol Rev. 2012;15:247-277.

21. Andersson GW, Miniscalco C, Gillberg N. A 6-year follow-up of children assessed for suspected Autism spectrum disorder: parents' experiences of society's support. Neuropsychiatr Dis Treat. 2017;13:1783.

22. DePape AM, Lindsay S. Parents' experiences of caring for a child with Autism spectrum disorder. Qual Health Res. 2015;25 (4):569-583.

23. Engstrand RZ, Roll-Pettersson L. Inclusion of preschool children with autism in Sweden: attitudes and perceived efficacy of preschool teachers. J Res Spl Educ Needs. 2014;14(3):170-179.

24. Gäreskog P, Lindqvist G. Working from a distance? A study of special educational needs coordinators in Swedish preschools. Nordic Stud Educ. 2020;40(1):55-78.

25. Anglim J, Prendeville P, Kinsella W. The self-efficacy of primary teachers in supporting the inclusion of children with Autism spectrum disorder. Educ Psychol Pract. 2018;34(1):73-88.

26. Soto-Chodiman R, Pooley JA, Cohen L, Taylor MF. Students with ASD in mainstream primary education settings: teachers' experiences in Western Australian classrooms. Austr J Special Educ. 2012;36 (2):97-111.

27. Boujut E, Dean A, Grouselle A, et al. Comparative study of teachers in regular schools and teachers in specialized schools in France, working with students with an Autism spectrum disorder: stress, social support, coping strategies and burnout. J Autism Dev Disord. 2016;46(9):2874-2889.

28. Imms C, Granlund M, Wilson PH, Steenbergen B, Rosenbaum PL, Gordon AM. Participation, both a means and an end: a conceptual analysis of processes and outcomes in childhood disability. Dev Med Child Neurol. 2017;59:16-25.

29. Ginner Hau H, Selenius H, Björck Åkesson E. A preschool for all children? - Swedish preschool teachers' perspective on inclusion. Int J Inclusive Educ. 2020;8:1-19.

30. Larcombe TJ, Joosten AV, Cordier R, Vaz S. Preparing children with Autism for transition to mainstream school and perspectives on supporting positive school experiences. J Autism Dev Disord. 2019;49(8):3073-3088.

31. Kvale S, Brinkmann S, Torhell S. Den Kvalitativa Forskningsintervjun (Swedish.). Studentlitteratur; 2014.

32. Kelly S. Qualitative interviewing techniques and styles. In: Bourgeault I, Dingwall R, de Vries R, editors. The Sage Handbook of Qualitative Methods in Health Research. Thousand Oaks: Sage Publications; 2010.

33. Kantzer A, Fernell E, Gillberg C, Miniscalco C. Autism in community pre-schoolers: developmental profiles. Res Dev Disabil. 2013;34 (9):2900-2908.

34. Elo S, Kyngäs $\mathrm{H}$. The qualitative content analysis process. $J A d v$ Nurs. 2008;62(1):107-115.

35. DeSantis L, Ugarriza DN. The concept of theme as used in qualitative nursing research. West $J$ Nurs Res. 2000;22(3):351-372.

36. Clarke V, Braun V. Thematic analysis. J Posit Psychol. 2017;12, (3):297-298. 


\section{Publish your work in this journal}

Neuropsychiatric Disease and Treatment is an international, peerreviewed journal of clinical therapeutics and pharmacology focusing on concise rapid reporting of clinical or pre-clinical studies on a range of neuropsychiatric and neurological disorders. This journal is indexed on PubMed Central, the 'PsycINFO' database and CAS, and is the official journal of The International Neuropsychiatric Association (INA). The manuscript management system is completely online and includes a very quick and fair peer-review system, which is all easy to use. Visit http://www.dovepress.com/testimonials.php to read real quotes from published authors.

Submit your manuscript here: https://www.dovepress.com/neuropsychiatric-disease-and-treatment-journal 